Thorax (1952), 7, 156.

\title{
THE SO-CALLED MIDDLE LOBE SYNDROME
}

\author{
BY
}

\author{
BJARNE FRETHEIM \\ From the University Hospital, Department A, Oslo, Norway
}

(RECEIVED FOR PUBLICATION FEBRUARY 25, 1952)

Chronic atelectasis and pneumonia of the middle lobe have been described as a clinical syndrome, of which the essential pathological feature is an obstruction of the middle lobe bronchus. The cause of obstruction may be intraluminal or extraluminal, specific causes such as tumour or active tuberculosis not included.

Graham, Burford, and Mayer (1948) reported 12 cases in which the syndrome resulted from enlargement of lymph nodes surrounding the middle lobe bronchus causing compression of the bronchial lumen and inflammatory changes with constriction. The chief symptoms were haemoptysis and recurrent pneumonia with intervening periods of malaise and weakness.

The reason for the middle lobe being affected more frequently than other lobes is, according to Brock $(1946,1950)$, that the middle lobe bronchus is exceptionally long and narrow and surrounded by lymph nodes draining not only the middle lobe but the lower lobe as well. Brock (1950) has also shown that a lymph node situated just below the middle lobe bronchus is the one most frequently involved and that previous tuberculous infection is the commonest cause of the lymphadenopathy. The infection causes tuberculous lymphadeniti, which, in turn, may give rise to caseous necrosis with deposition of lime salts resulting in a peribronchial fibro: is and constriction of the middle lobe bronchus. In some instances perforation and stricture may occur, in others broncholiths. The result will be atelectasis, infection, fibrosis, bronchiectasis. Brock calls this "the post-tuberculous middle lobe syndrome," and states that it occurs twice as often as similar involvement of the remaining parts of the lungs. Non-specific bronchostenosis, as described by Leegaard (1945), Fabritius and Ødegaard (1948), and Paulson and Shaw (1949), may produce a similar clinical picture. Bronchogenic carcinoma arising in the middle lobe bronchus is, according to Brock, a rare occurrence.

During the past five years 40 cases of posttuberculous or non-specific bronchostenosis have been admitted in the Surgical Department $A$ of the University Hospital, Oslo. Among these case middle lobe involvement was observed in 19, which are analysed in the present paper.

\section{Aetiology}

An analysis (Table I) of the individual cases showed that seven of the patients presented clear-cut symptoms of previous tuberculous infection as indicated by thepresence of tuberculous allergy and calcified lesions

TABLE I

AETIOLOGY

Post-tuberculous bronchostenosis

Non-specific bronchostenosis

Post-tubercu'ous or non-specific bronchostenosis $\quad .$.

in the lungs. In these cases calcified lymph nodes were seen adjacent to the middle lobe bronchus, and in one of them calcified foci were demonstrated in the middle lobe. Five patients were Pirquet-negative without demonstrable calcified lesions in the lungs. Neoplasm or active tuberculosis was not demonstrated in any of the cases.

\section{HISTORY}

A history (Table II) of frequent colds, particularly during autumn and early spring, was obtained in moss cases. Seven patients gave a history of bouts of pneu

TABLE II

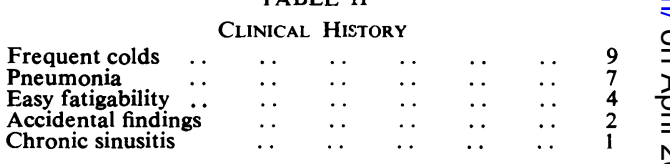

monia, and one had had chronic purulent sinusitis Weakness was the only complaint in four cases. Twoo were detected incidentally on chest survey.

\section{SYMPTOMS}

The symptom (Table III) most frequently causing the $\frac{\Gamma}{\varnothing}$

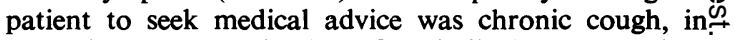
many instances productive of periodical expectoration. $\square$ Seven patients had had haemoptysis on one or severalo occasions, and five had had abundant expectoration, in

TABLE III

SYMPTOMS

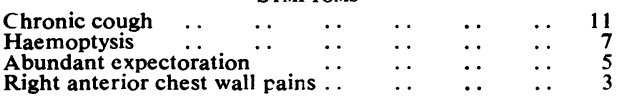


some instances foetid, suggesting bronchiectasis. In three cases the chief complaint was pain in the right side of the chest.

\section{BRONCHOSCOPY}

Bronchoscopy (Table IV) showed stenosis of the orifice of the middle lobe bronchus in only four cases of 19, whilst congestion and oedema of the ostial mucous membrane were demonstrated in seven. In the remaining cases bronchoscopy was negative. Biopsy and cytological examination in no instance showed evidence of tumour or tuberculosis.

TABLE IV

BRONCHOSCOPIC FINDINGS

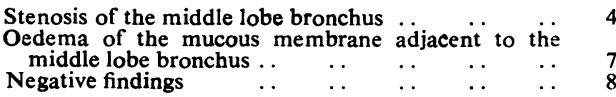

\section{RADIOGRAPHIC FINDINGS}

The radiological changes (Table $\mathrm{V}$ ) in many instances may be easily overlooked on antero-posterior films, as they may be hidden by the hilar shadow. But in the lateral view the changes are usually easily observed, taking the appearance of atelectasis of the middle lobe with evidence of fibrotic changes and bronchiectasis. In six cases a calcified lymph node was seen adjacent to the middle lobe bronchus, and in one calcified lesions were demonstrated in the middle lobe.

TABLE V

TOMOGRAPHIC FINDINGS

Atelectasis and fibrosis of the middle lobe $\quad \ldots \quad$.. $\quad 19$

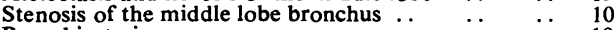

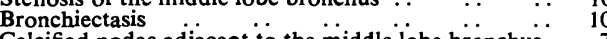

Calcified nodes adjacent to the middle lobe bronchus

10
7
7

On tomography, the changes are best visualized in the lateral views, which revealed stenosis of the middle lobe bronchus in 10 cases. In most cases the constriction was situated 1 to $2 \mathrm{~cm}$. from the bronchial orifice as described by Brock (1950), this being considered the reason for its not being detectable through the bronchoscope. Bronchiectasis was demonstrated by tomography in 10 cases. Radiological evidence suggestive of tumour was revealed in a single case only.

Tomography usually shows the bronchial tree so distinctly that bronchography is not necessary. In the few instances where this was not the case bronchography was performed and revealed stenosis of the middle lobe bronchus, bronchiectasis, and approximation of the bronchi as a result of the middle lobe shrinking.

\section{TREATMENT}

Nine cases were operated on and the middle lobe was resected in eight. Extirpation of the lung was performed in one where malignancy could not be excluded. In

TABLE VI

TKEATMENT

Conservative treatment
Middle lobe lobectomy

Pneumonectomy .. all these the diagnosis was verified by patho-anatomical examination which showed atelectasis of the middle lobe, chronic inflammation, and bronchiectasis. A lymph node firmly adherent to the middle lobe bronchus was found in four cases, and perforation in the middle lobe bronchus associated with a broncholith within a bronchiectatic cavity in one.

All patients undergoing lobectomy survived the operation. Serious post-operative complications were not observed, except in one patient in whom abundant expectoration persisted. Six of the patients operated on were re-examined six months to four years after the operation; five of them are now clinically well. One patient, in whom expectoration persisted after the operation, still has moderate expectoration. The other three patients have not come for re examination.

Of those not operated on, all except two have been re-examined once or several times. In these patients the symptoms were moderate and did not warrant operative treatment. Four of these patients later stated that they felt entirely well; in two of them moderate regression of the atelectasis was observed. In the remaining cases the condition remained unchanged.

\section{Discussion}

The recognition of the so-called "middle lobe syndrome" as a separate syndrome is scarcely justified because it is neither an aetiological, clinical, nor pathological-anatomical entity. If the concept is limited to post-tuberculous and non-specific bronchostenosis with chronic atelectasis and inflammatory changes of the middle lobe, the term may be justifiable. A definite stenosis of the bronchus, however, is not a constant finding, and, although bronchiectasis is usually present, it is not always so. Still, the retention of the term may be justified for practical purposes, as the changes mentioned are a far more frequent occurrence in the middle lobe than in the other lobes.

Brock (1950), who has published the largest and most thoroughly investigated series, viz., 60 cases of bronchostenosis of the middle lobe resulting from a previous tuberculous lymphadenitis, states that the incidenc: of bronchostenosis of similar origin in the other lobes was half of that in the middle lobe. This accords with our experience. Among the 40 cases of post-tuberculous or non-specific bronchostenosis observed in my department, affection of the middle lobe bronchus was observed in 19 cases. According to the anatomical structure of the lungs the left lingular segment might be expected to be the part of the lung next frequently involved, but this has not been our experience. Brock's (1950) statement concerning the relation between the anatomical structure of the middle lobe and the distribution of the lymph nodes consequently seems the only acceptable view. 
A differentiation between post-tuberculous and non-specific bronchostenosis of the middle lobe does not serve any purpose. In the present series, previous tuberculosis could be excluded in five cases, as indicated by a negative Pirquet test and the absence of other signs suggesting previous tuberculosis. In seven cases a previous tuberculous infection was proved as indicated by a positive Pirquet test, but on the other hand a non-specific infection could not be excluded as the cause of the bronchostenosis. In seven cases a healed tuberculous lesion could be presumed to be the aetiological factor.

The essential problem of practical importance is that concerning bronchogenic carcinoma. The radiological findings, the results of bronchoscopy, including biopsy and cytological examination, will be of determinant importance. In the present series there was one case where the probable diagnosis was carcinoma. Operation, however, revealed a non-specific bronchostenosis. On the other hand, negative findings do not exclude carcinoma. According to Brock (1950) carcinoma of the middle lobe is a rare occurrence. In a series of 1,200 cases of bronchogenic carcinoma he found only eight cases with the tumour arising in the middle lobe. This does not accord with our experience. Among 125 cases of bronchogenic carcinoma we found 11 cases with evidence of the tumour arising in the middle lobe. This is such a high incidence that the possibility of carcinoma must always be considered.

In some of the cases operated on the operation was actually performed because carcinoma could not be excluded. The subjective symptoms of these patients could not be said to warrant thoracotomy. In the other cases operated on the clinical symptoms were the main indication for surgery. When operation is recommended, it is far from simple, as the fibrous changes in the pulmonary hilus may be so severe that a pneumonectomy has to be performed instead of a lobectomy as planned. But the results of lobectomy have been so good that operation should be recommended in patients who haze disability due to the disease.

A greater problem will be involved when $t$ 尔 patient has no major complaint or in the case of incidentally detected atelectasis of the middle lobe in otherwise healthy subjects. In such instances there are sufficient reasons for adopting a conservative attitude provided malignancy can be excludes. Among the patients not operated on in the present series regression of the atelectasis was later observed in two cases. In our department we recommend that such cases if possible are re-examined every three months during the first year of observation. I

\section{SUMMARY}

An analysis has been made of 19 cases of the so-called "middle lobe syndrome" of either posttuberculous or non-specific origin.

Frequent colds, chronic cough, and haemoptysis were the essential clinical manifestations. In to cases the lesion was detected incidentally in apparently healthy individuals.

The bronchoscopic findings were of little sigi ficance. The radiological findings consisted f atelectasis and fibrosis of the middle lobe; in 90 cases bronchiectasis and stenosis of the middle lobe bronchus were found, and in seven cases a calcificd lymph node adjacent to the middle lobe bronchus.

Ten cases were treated conservatively, while niphe underwent surgical procedures, partly because malignancy could not be entirely excluded.

\section{REFERENCES}

Brock, R. C. (1946). The Anatomy of the Bronchial Tree. Londen (1950). Thorax, 5, 5.

Fabritius, H. F., and Ødegaard, H. (1948). Acta radiol., Stockh. 30 ,

Graham, E. A., Burford, T. H., and Mayer, J. H. (1948). Postgled. Med., 4, 29.

Leegaard, T. (1945). Acta oto-laryng., Stockh., 33, 391.

Paulson, D. L., and Shaw, R. R. (1949).. J. thorac. Surg., 18, 740 